\title{
Drumbeats in Modern Life
}

\section{Peter Wood}

Published online: 28 September 2011

(C) Springer Science+Business Media, LLC 2011

Deep in the footnotes of his marvelously varied, sometimes crotchety, always provocative, and overall splendid new book, The Tribal Imagination, Robin Fox offers an arresting two paragraph "Digression on David Schneider." What's arresting is Fox's generosity towards a man whom he might well excoriate. Schneider's 1984 attack on the study of kinship, A Critique of the Study of Kinship, was the signal event that marked anthropology's epochal turn against its core subject. Schneider granted a kind of permission slip to a generation of anthropologists-Fox refers to them as "the hordes of analytically challenged baby boomers" then flooding into the discipline-to indulge in free-form speculation about "culture" without having to understand, much less master, the difficulties of kinship theory.

Clifford Geertz's "interpretive anthropology" may loom larger in contemporary thought as the source of the highly politicized and intellectually shabby work that now passes for anthropology, but Schneider did the deeper damage by offering a seemingly authoritative reason to set aside most of the preceding 150 years of systematic anthropological inquiry. Schneider held open the door through which poured would-be anthropologists who had, at best, a cursory grasp of descent, filiation, marriage systems, moieties, genealogical method, and complex debates over social structure and social evolution that had comprised the main work of the discipline. Having chopped down the orchard, Schneider didn't have much to say about the weeds that came to luxuriate in the newly opened field.

\section{P. Wood $(\bowtie)$}

National Association of Scholars,

1 Airport Place, Suite 7,

Princeton, NJ 08540-1532, USA

e-mail: pwyattwood@gmail.com
With the death of Claude Levi-Strauss in 2009, Fox is perhaps the most important living exponent of the older tradition in anthropology in which the study of kinship was indeed the central intellectual enterprise. He is not alone in carrying this tradition forward but the number of anthropologists who are able to make active contributions has dwindled to perhaps a few dozen, most of them in the twilight of their careers. They bring to mind one of those soon-to-be-extinct languages in which the last native speakers are left to console each other in words that are beyond the reach of their heirs.

Fox might well then have had some harsh things to say about Schneider, but on the whole he is mild, and tempered with personal familiarity: “'Kinship,' according to Dave (who was something of a trickster and was probably playing a cruel joke on anthropology) is an ethnocentric invention based on European notions of bilateral relatedness..." He puts more of the blame on the anthropologists who fell for Schneider's “intellectual scorched - earth policy." Schneider (1918-1995) after all was one of the initiated, an anthropologist famed for his studies of matrilineal kinship systems, who only late in his career-1984, at age 66-made his abrupt about face, declaring "kinship" to be nothing more than an anthropological illusion. Perhaps Fox's message is that we should have an indulgent attitude towards tribal elders who get up to a bit of mischief.

Anthropologists who have followed Fox's long career will supply for themselves this missing context. Readers coming fresh to The Tribal Imagination, however, might be puzzled by the crusty and sometimes defensive tone of the book. Fox knows how far he is outside what now passes as the mainstream of anthropology. The Tribal Imagination is his summons to a new generation to return to key questions that were left hanging during anthropology's long vacation from intellectual seriousness. 
Whether that summons will reach receptive ears is hard to say, although "ears" is the right metaphor. Fox has an acoustical imagination, and his insistent theme- that we carry in our brains and our current civilization the key characteristics of our evolutionary past-is summarized as the tribal "drumbeats" that persist in modern life despite our claims to have liberated ourselves from the cruder stages of human development. In listening for these drumbeats, Fox walks us through an unexpectedly wide circuit of topics: how we perceive the flow of time; the built-in tendency of human groups (including academic groups) to split along sectarian lines; the multiple (and conflicting) accounts of the Ten Commandments in Exodus; incest in mythologies and literature, including shadows of incest in unexpected places such as Jane Austen's Mansfield Park; male bonding depicted in warrior epics; the frequency with which Algernon Charles Swinburne rhymed "death" and "breath;" and the existence of at least a handful of societies that reached a fairly complex state of development (Northwest Coast Indians, the Calusa of Gulf Coast Florida, and the Supe River people of coastal Peru, 3,500-1,600 BC) without agriculture and by relying instead on abundant marine resources.

Reduced to such a miscellany of topics, the book sounds unwieldy. Most of the chapters, indeed, originated as standalone essays published elsewhere, but Fox has done more than thread them together. The pieces are unified, as Fox puts it in his Prologue, as a study of "mind and society," in which the "power of the past on the present" is tracked through what anthropologists used to call "the comparative method." That is to say, Fox derives (mostly by induction) generalizations about tribal and band societies and asks if and how these generalizations play out in the modern West. In a chapter based on an essay first published in Society ("Sects and Evolution," 2004), for example, he argues that modern religious and political sectarianism is not just rhetorically "tribal" in character but in fact builds on a fundamental human drive rooted in our tribal past. We know, for example, that over the long course of human evolution, the groups in which humans lived regularly split up, or as Fox puts it, "Groups do not grow indefinitely large." We also know quite a bit about the mechanisms of this dispersal, as well as the means by which human societies maintain some bonds between the dispersed groups. Kinship provides both the glue that holds groups together in tribal society and the template for their splitting apart. Fox says the "manageable interactive group" for humans "has an upper limit of 150 individuals." Beyond that, the pressure grows rapidly for group fission.

If that rule is too exacting to apply in a literal sense to groups in mass society, we need only look at the lower levels of aggregation. The American Anthropological Association may have 10,000 North American members but "divide that by forty official 'interest groups' and you get an average of membership of 250." Fox finds this same fissiparousness in language, religion, political parties, and social movements - not playing out according to a single set of rules, but in obedience to a single underlying imperative. We need to belong to groups scaled to the level of interaction that our primate neocortext can handle.

His argument about the tribal "drumbeat" in contemporary sectarianism is among the simpler of Fox's excursions on this theme. Some of them require a modest amount of technical understanding of kinship theory and all of them require a reader willing to dwell at length on expository details. The arguments do not lend themselves especially well to terse summaries.

But that is not to say that Fox loses himself in the details. He is lucid and fascinating throughout.

The Tribal Imagination may be as close as we are likely to come these days to a vision of a comprehensive social science, one that asks large questions, proposes large answers, and is open to the full range of human experience. There are no walls in his approach dividing anthropology between scientific and humanistic concerns; no compartmentalizing of linguistic, historical, and ethnographic data. The price of entry into Fox's anthropology is willingness to take seriously the biological part of our heritage, but Fox doesn't take this as grounds for ignoring the mind or treating culture as a peripheral matter. ("Nature can implant a learning device as well as an instinct, and this has the adaptive advantage of flexibility, or varying responses to varying environments.") One of the attractions of his synthesis is the ease with which Fox moves between what others would segregate as hard science and humanities.

What then are these large questions? The three that strike me most forcefully in The Tribal Imagination are:

How well grounded is the West's confidence in democracy?

How deeply rooted are our needs for kinship? For friendship? For recognition?

Can we attain a universal history of mankind?

These questions can be phrased in a variety of ways to illuminate different aspects of the problems they enunciate. The first question swims in the vicinity of Francis Fukuyama, and he and Fox have had an interesting dialog, carried out in part in this book and Fukuyama's new work, The Origins of Political Order: From Prehuman Times to the French Revolution (2011). Fox is (characteristically) generous to Fukuyama but is skeptical that liberaldemocratic-capitalist societies with their emphasis on equality are the destined goal of mankind. The hitch is that such societies may have "simply become too complex and too expensive to sustain" in light of our all too human need for the psychological comforts of a closed society. The 
"authoritarian capitalism of Singapore and China, and the traditionalist and familial capitalism of Japan" might offer more viable alternatives. And "some form of theocratic capitalism might emerge in the Muslim societies." Fox approves of Fukuyama's hypothesis that we are not just rational creatures but creatures with an "evolved need" to be social. "Fukuyama handsomely acknowledges all that," but Fox offers a less sanguine conclusion: "But in the end what is there is the savage mind, and in the end that is us, and is both our limit and our hope. We shall never be freed from the tribal imagination as we might be freed from a particular form of economic or political experiment. The result of these experiments in civilization that we call history is still in doubt, and the experiments may well come to an end, but the savage mind is with us forever."

Fox, a student and admirer of Karl Popper, unquestionably prefers open societies, but he has a stern lesson for those who think openness will ultimately prevail in contests with the alternatives: "The whole premise of this book has been that the default system of human nature, and hence human society, is the tribal system; unquestionably Closed."

\section{How Deeply Rooted Are Our Needs for Kinship? For Friendship? For Recognition?}

Fox clearly sees kinship as a fundamental — which puts him at odds with contemporary (post-Schneiderian) anthropology. Anthropology has begun a tentative rapprochement with the study of kinship. Feminists, in particular found that, having joined in the parricide, they were bereft without the study of patterned and normative relationships. The new kinship studies, however, are dominated by the idea that "relationship" floats in an amniotic sea of possibility, with no necessary connection to biological constraints or structural imperatives. For Fox, this is all nonsense. Kinship is a reality that wasn't invented yesterday. We are as a species not just primed for but, in many ways, wired to the patterns that heterosexual mating, generational hierarchy, male bonding, fatherhood, motherhood, and extended kin relations have imposed on us. These patterns are not all nicely aligned with each other. They contain their own conflicts and stresses between competing priorities. We should shun incest and marry out, but how far out? (The tribal verdict is usually as far as cross-cousins and no further.) Men need to be loyal to their wives, but survival often depends on being even more loyal to our buddies. Women can be both "enabling" to the hero and fatally disabling. The stories we tell ourselves-and have always told ourselves - play out the unresolvable tensions among these demands.
Since we are a society now on the verge of radically redefining marriage and family, Fox's reminders of the fixed points are especially timely. We have immense flexibility to conjure new institutions-gay marriage, fatherless-by-design children, polyamory - and a seeming obliviousness to the possible consequences beyond gratifying our "open society" urge to maximize individual freedom. Fox doesn't weigh into these specific debates, but the drumbeats of our tribal past would seem to be tapping out a warning that the unfettered pursuit of civil liberties will not be the end of the matter.

\section{Can We Attain a Universal History of Mankind?}

Fox dedicates The Tribal Imagination to the memory of Claude Levi-Strauss and Ernest Gellner, anthropologists who brought large intellectual horizons to their work. Neither of them, however, shared Fox's deep commitment to evolutionary thinking. They were each, in different senses of the word, structuralists, for whom the deep past of any society was a less fruitful source of insight than recent and present circumstances. Fox is cut from different cloth. $\mathrm{He}$ sees the present as everywhere infiltrated with the legacies of a long tribal pre-history. This light shines through the whole book but it comes into particular focus in a chapter towards the end, "The Route to Civilization: From Tribal to Political Society." The title touches again on Fukuyama's present concerns but even more deeply it echoes the work of the founder of American anthropology, the New York lawyer Lewis Henry Morgan (1818-1881).

Morgan hasn't been entirely written out of anthropology. $\mathrm{He}$ is usually just mentioned in undergraduate courses and typically dismissed in graduate school as an obsolete "social evolutionist," for whom memorization of a second or third-hand dismissal is all that is needed. Morgan is remembered as well for the use to which Friedrich Engels put him in The Origin of the Family, Private Property, and the State. Engels mined Morgan's last book, Ancient Society, in an attempt to de-naturalize the bourgeois family system and launch a whole flotilla of Marxist speculations that had only tangential connection to what Morgan actually wrote.

Morgan ought to be considered one of the great figures in American science and Fox does an important service here by insisting that, when later generations of anthropologists pointed out significant intellectual errors in Morgan's theories, they carried their indictment too far. Morgan's first book, The League of the Ho-de-no-sau-nee or Iroquois (1851), was the first scientifically-minded American ethnography. Though he was not the first observer to take note of Iroquois matrilineages and how the seemingly unusual Iroquois kinship terminologies 
matched their larger patterns of social life, he was clearly the first to glimpse the deep accord between a tribal kinship system and a tribal political organization. The recognition fired his imagination and he set out to discover how widespread such patterns might be-traveling the American West to visit as many tribes as possible and sending letters of inquiry around the world. The result of this massive undertaking was a no less massive work of scholarship, Systems of Consanguinity and Affinity in the Human Family (1871), which placed the study of kinship as the cornerstone of the new discipline.

Morgan was above all interested in the "progress" of mankind, from our most primitive state to Western civilization as it then stood. For him, the great dividing line was between societies based on kinship, such as the Iroquois, and the rise of the political state that subordinated kinship to the rule of impersonal law, such as happened in both ancient Greece and Rome. He made some bad assumptions in synthesizing this picture. He assumed, for example, that all societies pass through the same developmental sequence. Recall those tribes without agriculture that rose to a fairly complex level of social organization by relying on fishing - a state of affairs that contradicts Morgan's scheme of things. Morgan also incorrectly deduced that kinship terminologies could be "read back" as straightforward representations of how people conceived of their biological relatedness. In a generation or so, this was recognized as error, and anthropologists begansometimes with vehemence - to take such errors as grounds for abandoning Morgan's larger project: the attempt to see all of humanity in a single developmental perspective.

Fox calls us to restore this project. "For those of us who still believe that anthropology is a discipline anchored in evolution and needing all the forces of paleontology, genetics, archaeology, linguistics, history, and ethnography to tell the whole human story that is its brief, a hard second look at the perfect integration that Morgan's comparative method offered us will do no harm."

Indeed, it might do a lot of good. And The Tribal Imagination is a winsome invitation to try it out. It is, however, an invitation coming late in the day. Anthropology is now populated with Ph.D.s lost in the funhouse of postmodernity and innocent of any understanding of kinship, let alone Morgan's astonishing insight of how kinship systems interlace with the larger social order. Fox has offered a dazzling display of the intellectual power available in these old runes. But how likely is it that anthropology will take up the challenge? There is something tribal about anthropology itself in its tendency to create a closed community of its own.

In November 2010, the Executive Board of the American Anthropological Association discussed a new long-range plan that would alter the AAA's mission statement. The new mission statement deleted the idea that anthropology is a science and inserted a stronger warrant for using anthropology to engage in public advocacy. A storm of criticism followed, mostly from anthropologists who persist in thinking of their discipline as a science. The Executive Board offered some mollifying assurances, but I am not clear as of this point where the matter stands. The controversy is a sign that not all is lost. The initial readiness of the Executive Board to jettison the word "science" as a description of the core pursuit of anthropology, however, speaks loudly of how far Morgan's legacy has declined and how large a change Fox is calling for.

Peter W. Wood is president of the National Association of Scholars. He is a former professor of anthropology and college provost and author of $A$ Bee in the Mouth: Anger in America Now (Encounter Books, 2007) and of Diversity: The Invention of a Concept (Encounter Books, 2003). 